\title{
Stability or Variability: Promising Models for the Development of Territorial Systems
}

\author{
Yushkova N.G. \\ National Research Moscow State University \\ of Civil Engineering, \\ Moscow, Russia, \\ Volgograd State Technical University, \\ Volgograd, Russia, \\ dontsovushkova@mail.ru
}

\author{
Fikhtner O.A. \\ Yaroslav-the-Wise Novgorod State University, \\ Veliky Novgorod, Russia, \\ Oxana.Fikhtner@novsu.ru
}

\begin{abstract}
The research formulates the scientific problem of the reorganization of territorial systems in modern conditions, caused by the pronounced polarization of the space of life. The methods currently used to solve it do not classify the methods of functioning of territorial systems in terms of their acquisition of an analog form; this is a consequence of the combination of the requirements of the process innovation and their stability. Accordingly, the dependence of the concepts of their spatial development of territorial systems on management models is not revealed. The improvement of methods is associated with the differentiation of methods of providing managerial influences on territorial systems, with the allocation of priority management functions. The article shows that territorial systems are a special object of management, as the integrity and parts, in their interconnection, which determines the phenomenology of determining their features and characteristics. The analysis of the used management schemes based on various variants of interaction of functions made it possible to identify the structural elements of the change management mechanism. The identification of the characteristic principles of territorial systems management (differentiation, modification, conformity and closed loop), which form a model management scheme and ensure a high degree of its universality, has been substantiated. The completeness of their implementation is a condition for improving the efficiency of management. The priorities of management are highlighted, which allows for achieving optimal functioning of the management object. In the context of the system methodology, the mutual subordination of management mechanisms to the basic models of reorganization of territorial systems has been established, within which specific parameters of their changes are established. To increase the manageability of territorial systems, it is necessary to endow the authorities with new functions and forms of exercising their powers. The development of models of territorial systems is especially relevant for Russian regions, where both the starting conditions of socio-economic development and the methods of organizing the management action on territorial systems are highly differentiated.
\end{abstract}

Keywords—territorial systems, change management, indicators, system regional science, simulation

\section{INTRODUCTION}

The management of territorial systems is not a goal in and of itself, but a basic condition for their adaptation to the changing socio-economic situation. The manageability of territorial systems in the applied aspect of consideration means the progressive formation of their material-spatial environment as a reaction to external influences. They may not be unambiguous, and their consequences are not predictable, especially if we take into account the severity of the asymmetry of the processes of territorial development [1-3]. In addition, achieving conflict-free reactions of territorial systems is problematic and, to a greater extent, an exceptional option. Despite this, the state sought for territorial systems is the preservation of balance forms and the search for probable scenarios for their provision. This seems to be an important task of strategic management in the context of growing uncertainty of the influence of external factors. The management system being formed is designed, first of all, to restrain the possible negative impact of a large number of factors on the territorial systems, while ensuring a consistently high level of quality of life of the population and the most comfortable living conditions [4-7]. Such a system is in demand by the economy both at the level of a separate region, macroregion, and at the level of megaeconomics, regardless of the state structure, form of government and specific strategic goals and objectives of a particular state.

Despite the obvious differences between territorial systems, their functioning is becoming more and more analogous, which is a consequence of the need for their compliance with certain requirements. The requirements are largely due to the principles of sustainable development, recognized in all countries of the world for many years $[8,9]$. No less important are innovations that penetrate all spheres of public life. They are evidence of progress, as they cause changes in territorial systems and their parts [10]. The challenges of innovation cease to be only a selective factor in determining the characteristics of territorial systems and become a recognized factor in their development. As a consequence, in the interaction of the noted tendencies of 
sustainability and innovation, a contradiction is manifested between the vector contributing to renewal, modification, the formation of new elements of territorial systems and the vector ensuring the preservation of their stable state [11].

The search and substantiation of ways to resolve this contradiction contributes to the improvement of generally accepted methodologies.

At present, discussions about solving the problems of manageability of territorial systems and determining the most appropriate directions for their formation are not completed. According to modern researchers, the manageability of territorial systems can be evidenced by their rapid adaptation to a dynamically developing external environment [12-15], a homogeneous structural organization at the municipal and federal levels and the ability to reorganize them [16], the introduction of various technological innovations $[17,18]$.

Despite this, a number of aspects of the manageability problem require detailed study $[7,10,11]$. In particular, the conditions under which the efficiency of functioning of territorial systems is ensured have not been determined, the role of the authorities in the processes of territorial development has not been disclosed, the management tools used specifically for these purposes have not been classified, and their optimal combinations have not been determined. As a result, the development of scenarios for the reorganization of territorial systems is increasingly isolated from its methodological support. A few examples from the latest practice of managing territories show the possibility of providing real impacts on changing their state through the establishment of appropriate indicators using management tools. Thus, there is a relationship between changes in the conditions of functioning of territorial systems and the content of management decisions. In this direction, the authors of this study propose to consider the problem of manageability of the development of territorial systems.

\section{RESULTS AND DISCUSSION}

\section{A. Features of territorial systems as objects of management}

When managing territorial systems, it is customary to be guided by the methods of strategic management, which are traditionally used to solve the problems of the development of similar objects - complex systems that differ in physical size and the content of the processes occurring within them. Territorial systems are man-made objects. On the one hand, they have a complex nature of the interaction of the elements that form them, on the other hand, they are subject to the influence of various factors: economic, geographical, social, environmental, cultural, historical, technical, psychological and many others. The influence of such factors is compensated by the specificity of territorial systems, which causes the manifestation of special characteristics and new properties in the process of their functioning [10]. The specificity of territorial systems requires a special approach to the formation of the management system. Here, first of all, the principles determined by the predicted (sought) states of territorial systems are formalized, which becomes the basis for improving the management methodology. But at the same time, the significance of the classical principles of strategic management remains.

\section{B. Principles of territorial systems management}

The principle of differentiation of the management system predetermines the identification of such elements as the management object (managed system), to which the management influence is directed, and the subject of management, and establishes the order of their interaction. In the context of this study, it is proposed to understand the object of management in two ways: as a territorial system as a whole and as a set of its constituent elements. As a result of this division, the identified features of the behavior of territorial systems and possible options for their response to external influences are explained. The determined characteristics of management objects allow for ensuring the predictability of the results of management actions on them by management subjects. The different complexity of the management actions exerted on the object affects their profitability. And the intensity of changes in the characteristics of territorial systems depends on their power. As a result of the impact exerted on the object, its new (changed) state may significantly deviate from the current state, which may require reorientation of the functioning processes. In order for the actions of the subjects of management to acquire a directional character, to become more precise and specific, the parameters of territorial systems, and, accordingly, the indicators of their changes must be predictable.

The need to apply the principle of modification of the management system arises due to the moral or physical obsolescence of existing schemes, exhaustion of the resource, inconsistencies caused by the inconsistency of the status of the assigned management tasks and the capabilities of the functions involved in the management process. The modification is associated with the optimization of the structure of the management system. Therefore, it should reflect as much as possible the logic of interaction between individual functions and standardization of operations. When determining the methods for modifying the management system, one proceeds from the subject orientation of the activity, which determines the features of the organization of functional processes. The specificity of the management object causes the targeting of the formation of the management system and the use of each of its functions, the rejection of standard schemes and their individualization. This means the presence of fixed changes in territorial systems caused by their transformations. In this case, it is allowed to combine individual functions into functional (dominant) blocks. However, with any options for grouping management functions, the set goal should be achieved, assessed by the presence of specific positive results of management activities.

The principle of correspondence of management functions to the significance and the content of the tasks they perform implies the dependence of the type of impact on the management object on the expected final results of the activity. The establishment of the desired functional relationship is regulated, on the one hand, by clearly delineated strategic, tactical and operational goals and management tasks, and, on the other hand, by the directions of their implementation. The whole variety of functional capabilities of management systems can be represented by groups of functions (for example: planning, regulation, monitoring) and their combinations. In this case, the list of used management functions can be expanded if necessary. Attitudes to improve the efficiency of the management system dictate the way to use the available resource of the territorial system, the ways of grouping 
functions and their interaction, redistribution of flows and their speed. They are implemented in variants of the decomposition of the management system, adjusted in relation to the problems of specific territorial systems and depending on the formulated goals of their development.

The implementation of the principle of closed loop management ensures the continuity of the stages of management based on the construction of a closed loop on the principle of "technological chain" with the transfer of certain powers from one management function to another. The use of this principle increases the guarantees of the feasibility of the objectives set, excludes duplication of functions or insufficiently precisely directed use of them, and also prevents technical failures in the functioning of the management system.

When developing a management system, the significance of the general - traditional - principles is fully preserved. With regard to territorial systems, it is advisable to additionally take into account the principles identified in the framework of the study. Together, they form a model scheme for managing territorial systems and provide a high degree of its universality. In the process of designing a management system, the degree of participation of principles in the development of a complex of management actions, as well as their species diversity, is determined.

\section{Justification of management priorities}

Hypothetically, any of the management functions can be recognized as a priority. Of decisive importance in the final choice of priorities is the content of the processes occurring in the management objects. The presence of priorities in the management system means the establishment of a ranking of its elements, which makes it possible to achieve optimal functioning of the management object, first of all, in the consistency of its development in relation to the acquired order of the internal structure, not disturbed by the influence of external factors. Revealing the distinctive features of territorial systems leads to the adjustment of actions aimed at the territorial system by activating the mechanism of interaction of management functions.

In the classical management scheme, planning is the leading function. The functioning of the entire system depends on the degree of its activity. The advantages of planning are due to the possibilities of influencing the structure of the management cycle, individual actions in the management system, their sequence, the order of organizing the relationship of functions. In any case, within the framework of planning, long-term development scenarios are formed, decisions are made on the merger and coordination of operations, and the status of the activities being carried out is determined. Accordingly, conceptual rather than actual actions are developed. They are predominantly staged, "strategic" in nature. This means the obligation to develop the most complete set (complex) of measures of the "pioneer", experimental, unique properties. Then, at the subsequent stages of management, the existing justifications should be formalized and acquired detailed descriptions by establishing indicators of changes in territorial systems, affecting both main and accompanying processes.

The problems of managing territorial systems can have various solutions, but the choice should always be in favor of rational ones. Rationality is associated with an increase in the guarantees of the continuity of the functioning of the management system, the preservation of the continuity of functions and the most complete realization of the planning provisions. This can be achieved by transferring an impulse from the center (core) of the management system to the periphery, with its constant activation through the involvement of other management functions in this process, along with planning.

These managerial actions are the basic conditions for making the transition to the implementation of plans in the sphere of practical activity. The effectiveness of the management system requires ensuring the interaction of these characteristic stages of management. The evidence of interaction can be, for example, the constancy of maintaining existing structural ties, or the formation of new ties.

Considering the management system from these positions, it can be stated that the basis of its formation is the inextricable link between planning and regulation. If planning summarizes all the most important positions of the long-term development of the management object, then regulation is responsible for the direct implementation of a set of planned measures. The guarantees of their full-fledged implementation can be increased by combining and coordinating functional processes by influencing their structural connections. To ensure the continuity of management when justifying and developing management influences on the territorial system, special tools are formed and options for their interaction at various management stages are determined. Therefore, the functions of planning and regulation become comparable in importance, in each of them there is a cross translation of their initial features. Thus, the principle of direct and feedback links between strategy and tactics is implemented. Accordingly, the detailing of operations through regulation does not occur in isolation, but in full accordance with the strategic guidelines determined in the framework of planning.

The content of the regulation is strongly influenced by the specific context. Depending on it, the latent properties of regulation are manifested: flexibility, variability, the ability to generate various forms of manifestations. The presence of the specified regulation properties is important for their translation, but in the form of management tools. The methods of using tools within the framework of regulation should be tuned not only to formal compliance with changes in external conditions, but also to have a transforming ability leading to the achievement of specified indicators of territorial systems. Their classification and accounting are necessary to ensure the effectiveness of the management system, namely: when developing a complex of regulatory (management) influences on the territorial system, with an emphasis on the dynamics of processes, within the framework of the generated management technologies.

\section{System regulation of territorial development}

The methodology of system regional science (system methodology) as a direction of interdisciplinary research has a long history of formation $[1,2]$. It began in the late 1970s in connection with the actualization of methods for studying territorial systems. Until now, the Institute for Systems Analysis of the Russian Academy of Sciences (ISA RAS) continues research aimed at a detailed study and disclosure of various aspects of the system methodology in the aspect of territorial development. As a result, a large number of fundamental and 
applied works that reveal the conceptual provisions of the system methodology have appeared. To substantiate the methods of organizing territorial systems, the following concepts are used: "state of the system" and "development of the system". In the first method, it is decisive to take into account the state of the territorial system, which makes it possible to form its spatial structure through the proportional distribution of material objects in it. The ambiguity of the state of territorial systems is the result of their functioning caused by the influence of various external factors. Perception of these external influences by the territorial system is multivariate and is described by a number of specific indicators. In the second method, the functional organization of the territorial system is ensured by building rational relationships between numerous objects, and, if necessary, transforming them to ensure the development goals of the territories. In this case, when different ways of the processes in the system cause changes in the indicators of the territorial system in time, we are talking about its development.

The cumulative result of the interaction of both of these methods is the achievement of certain functional-spatial effects in territorial systems. Diagnostics and assessment of territorial systems makes it possible to identify the problems of their existing state, which determines the direction and specifics of the impacts: the organization or reorganization of the materialspatial environment.

One of the most important achievements of the system methodology is the concept of system regulation, which operates with the concept of "functional-spatial organization" of territorial systems. Its content is revealed by the following provisions: the study of the conditions for the functioning of systems and the factors of their optimization, and the justification of a set of measures that can significantly change the parameters of the management object. The territorial systems' drive towards achieving certain indicators of changes in their state is determined mainly by the need for their renewal, in other words, in reorganization.

The regulation of functional and spatial changes cannot be considered an alternative to known means of regulation. They can retain their relevance, but when external conditions change, their management ability decreases. Especially if the course of transformation processes in territorial systems demonstrates noticeable fluctuations $[5,11,16,19]$. But even in this situation, the requirements for adjusting the management system to improve the effectiveness of the processes of reorganizing territorial systems as part of management decisions must be observed, which must be taken into account when searching for new means [20, 21]. For this purpose, a set of impacts on the conditions, priorities and limitations of the functioning (transformation) of individual elements of territorial systems and (or) the interrelationships between them is specially organized in order to resolve territorial-economic, administrative-territorial and other contradictions, and to ensure on this basis a comprehensive and balanced reproduction potential of their development.

The most important substantial component of the concept of systemic regulation is a special technology that ensures the effectiveness of system management mechanisms. Its core is regulators that must meet the following requirements:

- have the ability to systematically influence the territorial system as a whole and on each of its elements;
- simultaneously influence the greatest possible number of such elements, as well as their interactions.

In other words, they are required to provide a systemforming impact on territorial systems aimed at both individual and aggregate results. As a result, regulators, due to the pointdirected use of the potential, can have a single effect on the management object. In addition, they are able to form a kind of integrity from many simultaneously connected regulators.

System regulators, possessing characteristic features, as part of the mechanism of system impact on the territorial system, can only have a purpose, excluding situational behavior. Their fundamental importance is:

- in removing potentially possible contradictions in the functioning of elements of territorial systems;

- in bringing its individual elements into a system unity;

- in an orientation towards mutual accounting and coordinated realization of interests both in the territorial system as a whole and in dependent structures, the interrelations of which form the cycles of functionalspatial development.

The involvement of regulators in the process of system regulation presupposes a sequence of transition to a new level in the management of territorial systems: from private disparate tools to separate organized fragments of mechanisms, and then to the formation of system mechanisms of influence on individual relations, spheres and interests of functional-spatial development. It is natural to assume that system regulators are obliged to simultaneously introduce mutual restrictions in the relations and growth processes of individual elements of the territorial system that do not correspond to the ultimate goals of its development and prevent the preservation of balance states [22].

The sought-after result of the provision of management influences on the territorial system is its imbalance (Fig. 1). One of its most dangerous threats is the heterogeneity of the functional and spatial organization of the territorial system. It is due to the action of two diametrically opposite tendencies: uniform formation and polarized development.

The first tendency leads to the development of a basic model "Continuity of the structure", in which the interaction of geographically distributed zones and objects occurs through stably functioning links. In contrast to it, the second tendency "Infrastructure variability" is based on local urbanized formations, which, a priori, themselves are the "points of growth" of the territorial system, and also reveal the directions of its future development. In each of the models, characteristic groups of elements are distinguished, differing from each other in dynamism and readiness to change.

As a result, the elements that increase the stability of territorial systems and preserve their characteristics in the process of optimizing the management influence are concretized. After their identification, it is necessary to assess the functional and spatial dynamics of territorial systems. It is important to understand that such an assessment is not a onetime act, but periodically repeated manipulations that confirm or refute the correct choice of strategy and management tactics. The obtained data are used in the formation of a model of their reorganization, which provides for various options for taking 
into account the requirements when developing scenarios for both homogeneous and heterogeneous changes. An integral part of the models of reorganization of territorial systems is the development of the subject content of management functions $[23,24]$. It means that the measures implemented within the framework of regulation are based on the provisions formulated in the framework of planning and are subsequently analyzed using monitoring tools. Obviously, they should, on the one hand, form a strictly defined set of functional means that substantively characterize the selectivity of each of these actions, and, on the other hand, form integrity.
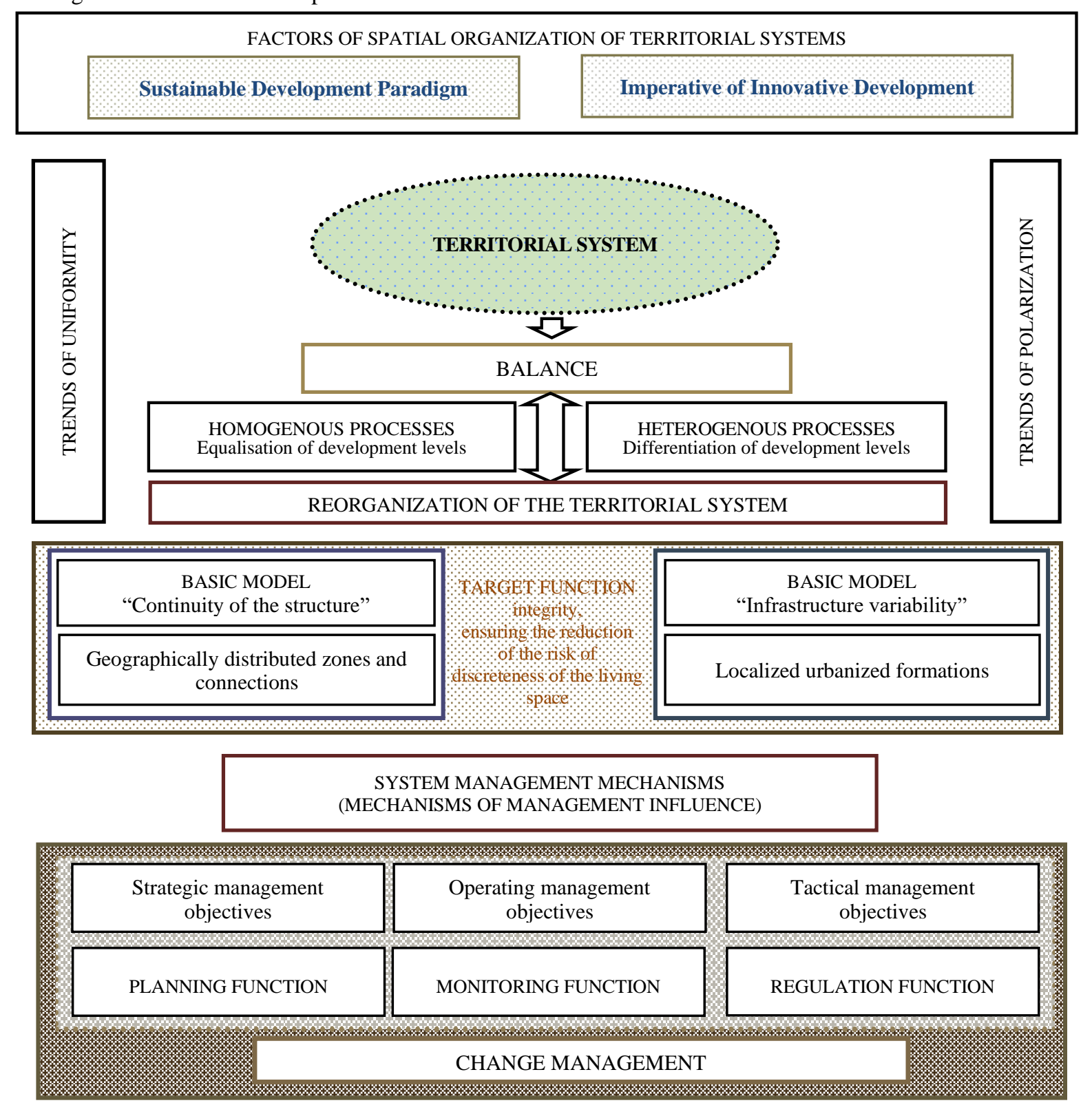

PARAMETERS OF CHANGES / INDICATORS / PROPERTIES AND CHARACTERISTICS OF TERRITORIAL SYSTEMS

Fig. 1. Schematic diagram of the formation of system mechanisms of change management, taking into account the specifics of territorial systems

In any case, ensuring the operability of this mechanism is the prerogative of state and municipal authorities. The practical application of the technologies of "system regulation" means the continuous interaction between the management functions that ensure the long-term, medium-term and short-term implementation of goals, and the tasks of the development of territorial systems, taking into account their regional identity.

\section{CONCLUSION}

The authors of the study presented an innovative approach to justifying the choice of a model for managing territorial systems, which is very universal in the face of global uncertainty, simultaneously with a clear focus on development. In the context of system regional science, mechanisms for 
managing changes at the territorial level are proposed through a permanent analysis of the parameters of changes to select the optimal combination of management functions and achieve a balanced state of territorial systems. The concept of system regulation made it possible to prove the need for a systemforming influence through a special mechanism - system regulators that ensure the transition to a new level in the management of territorial systems. Taking into account the territorial systems' pursuance of a balanced state, their reorganization takes place in the conditions of multidirectional processes of equalization and differentiation of the levels of their development. As a result, models of reorganization of territorial systems that satisfy these conditions have been developed, which allow for using the features of their dynamicity and readiness for changes. The basic model of reorganization "Stability of the structure" ensures the continuity of the existing functional-spatial relations of territorial objects, their effective interaction to ensure the goals of development of the territories. The basic model of reorganization "Infrastructure variability" was formed using the assessment of local urbanized formations from the point of view of their functional-spatial dynamics to identify the prospects for the development of territorial systems. The search for an optimal reorganization model that meets the development challenges of a particular territory is determined by the choice of an adequate management influence due to effective continuous interaction between management functions, which ensures the desired and predictable response of the system.

\section{Acknowledgment}

This work was supported by the Russian Foundation for Basic Research (project no. 18-19-001.18, Spatial and strategic development of territories)

\section{References}

[1] V.N. Leksin, "Towards methodology of the research and regulation of spatial development”, Region: Economics and Sociology, 2009, vol. 3, pp. 19-40. (In Russ.).

[2] A.N. Shvetsov, "Systematization of tools for long-term planning of territorial development: urgent need and concrete proposals" ["Sistematizatsiya instrumentov perspektivnogo planirovaniya territorial'nogo razvitiya: nastoyatel'naya neobkhodimost' i konkretnye predlozheniya"] (ending), Russian Economic Journal, 2009, vol. 5, pp. 12-47. (In Russ.).

[3] A. Wilson, "Entropy in Urban and Regional Modelling: Retrospect and Prospect”, Geographical Analysis, 2010, vol. 42(4), pp. 364-394.

[4] A.I. Tatarkin, "Regional targeting of the Russian economic policy: an institution for spatial planning of territories", R-Economy, 2016, vol. 2(1), pp. 1-16.

[5] P. Hall, Urban and Regional Planning, London: Routledge, 2002, 208 p

[6] C. Borrego, H. Martins, O. Tchepel, L. Salmim, A. Monteiro, and A.I. Miranda, "How urban structure can affect city sustainability from an air quality perspective", Environmental Modelling and Software, 2006, vol. 21(4), pp. 461-467.
[7] N. Yushkova, "Restructuring of regional long-term planning principles: adaptation or strategic choice", Technology Audit and Production Reserves, 2014, vol. 4(2-18), pp. 45-50.

[8] J. Huang, X.X. Lu, and J.M. Sellers, "A Global Comparative Analysis of Urban Form: Applying Spatial Metrics and Remote Sensing”, Landscape and Urban Planning, 2007, vol. 82(4), pp. 184-197.

[9] N.A. Kazhuro, "The conception of sustainable development as a new paradigm of social progress", Science \& Technique, 2016, vol. 15(6), pp. 511-520. (In Russ.).

[10] D.G. Dontsov, N.G. Yushkova, and E.G. Gushchina, "A new spatia strategy approach in Russian regions: from the reflexing planning solutions to territorial integration conception", IOP Conference Series: Materials Science and Engineering, 2018, vol. 463(3), 032055. DOI: https://doi.org/10.1088/1757-899X/463/3/032055

[11] N.G. Yushkova, E.G. Gushchina, D.G. Dontsov, and O.A. Fikhtner, "Spatial development dichotomy: assessment of the potential and implementation of territorial systems", in The European Proceedings of Social \& Behavioural Sciences, 2019, vol. 77, pp. 792-803

[12] E.A. Antipova, and L. Fakeyeva, "Settlement System of Belarus. Spatia and Temporal Trends at the End of 20th and the Beginning of the 21st Centuries", Journal of Settlements and Spatial Planning, 2012, vol. 3(2), pp. 129-139.

[13] L. Michalka, and B. Kovac, "A new tool of urban stability and development in spatial planning", IOP Conference Series: Materials Science and Engineering, 2019, vol. 471, 092046. DOI: https://doi.org/10.1088/1757-899X/471/9/092046

[14] Y. Jabareen, "Planning the resilient city: Concepts and strategies for coping with climate change and environmental risk", Cities, 2013, vol. 31, pp. 220-229.

[15] J. Sołtys, "Settlement Networks in Polish Spatial Development Regiona Plans", IOP Conference Series: Materials Science and Engineering, 2017 vol. 245, 042083. DOI: https://doi.org/10.1088/1757-899X/245/4/042083

[16] A.N. Shvetsov, A.N. Demyanenko, and V.N. Ukrainskiy, "Destructive stereotypes of Russian strategic planning and their possible consequences for the practice of regional strategy development" (part 1), Regionalistics, 2016, vol. 3(3), pp. 48-60. (In Russ.).

[17] V.A. Smilka, "Detection of reflexive signs in town planning systems of Ukraine and Republic of Belarus", Science and Technique, 2018 vol. 17(2), pp. 123-129. (In Russ.). DOI: https://doi.org/10.21122/22271031-2018-17-2-123-129

[18] P. Graboviy, "Reconstruction and modernization of industrial parks", in Proceedings of E3S Web of Conferences, 2019, vol. 91, 08028. DOI: https://doi.org/10.1051/e3sconf/20199108028

[19] A. Grimes, E. Apatov, L. Lutchman, and A. Robinson, "Infrastructure' long-lived impact on urban development: theory and empirics", Motu Working Paper, 2014, vol. 14-11. DOI https://doi.org/10.2139/ssrn.2517085

[20] N. Harris, and A. Hooper, "Rediscovering the Spatiall in public policy and planning: an examination of the spatial content of sectoral policy documents", Planning Theory and Practice, 2004, vol. 5(2), pp. 147-170.

[21] F. Le Néchet, "Urban spatial structure, daily mobility and energy consumption: A study of 34 European cities", CyberGeo, 2012, 580. DOI https://doi.org/10.4000/cybergeo.24966

[22] S.G. Vazhenin, and I.S. Vazhenina, "Competitive cooperation of territories as an economic reality", Region: Economics \& Sociology, 2017, vol. 2(94), pp. 191-209. (In Russ.). DOI: https://doi.org/10.15372/REG20170209

[23] P.A. Minakir, "Spatial development strategy: a view from the concepts of spatial organization in the economy", Spatial Economics, 2018, vol. 4, pp. 8-20. (In Russ.). DOI: https://doi.org/10.14530/se.2018.4.008-020

[24] O.V. Glushakova, Ya.A. Vaysberg, N.V. Fadeykina, V.V. Mikhailov, and V.A. Trifonov, "Architectonics and strategic architecture of regional public administration systems: assessment of compliance", in The European Proceedings of Social \& Behavioural Sciences, 2019, vol. 59, pp. 331-341. DOI: https://doi.org/10.15405/epsbs.2019.04.37 